\title{
Computational Fluid Dynamics: Hemodynamic Changes in Abdominal Aortic Aneurysm After Stent-Graft Implantation
}

\author{
Thomas Frauenfelder, ${ }^{1}$ Mourad Lotfey, ${ }^{2}$ Thomas Boehm, ${ }^{1}$ Simon Wildermuth ${ }^{1}$ \\ ${ }^{1}$ Institute of Diagnostic Radiology, University Hospital of Zurich, Zurich, Switzerland \\ ${ }^{2}$ Fluent Corp., Darmstadt, Germany
}

RE: Cardiovasc Intervent Radiol (2006) 29: 613-623 (this issue) - Several errors appear in the published online and print versions of this article in Table 3. In the table, the top heading on the right side should read "1-EIA-ratio per cardiac cycle." In column 3 , row 1 , the correct number is 0.75 . In column 3 , row 2 , the correct number is 0.95 . The complete Table 3 appears correctly below.

Table 3. Flow volume ratio of the right versus the left EIA

\begin{tabular}{|c|c|c|c|c|}
\hline & \multicolumn{2}{|c|}{ EIA-ratio per cardiac cycle } & \multicolumn{2}{|c|}{ 1-EIA-ratio per cardiac cycle } \\
\hline & Before & After & Before & After \\
\hline & \multicolumn{2}{|c|}{ Aortic stent-graft implantation } & \multicolumn{2}{|c|}{ Aortic stent-graft implantation } \\
\hline Patient 1 & 0.68 & 0.75 & 0.318 & 0.246 \\
\hline Patient 2 & 0.66 & 0.95 & 0.33 & 0.05 \\
\hline Patient 3 & 1.28 & 0.86 & 0.273 & 0.241 \\
\hline Patient 4 & 1.06 & 0.81 & 0.057 & 0.189 \\
\hline Patient 5 & 0.47 & 0.58 & 0.522 & 0.418 \\
\hline Patient 6 & 1.05 & 1.27 & 0.044 & 0.272 \\
\hline Patient 7 & 1.23 & 0.83 & 0.237 & 0.181 \\
\hline Patient 8 & 1.24 & 0.96 & 0.242 & 0.039 \\
\hline Patient 9 & 1.27 & 0.84 & 0.272 & 0.156 \\
\hline Patient 10 & 1.27 & 0.80 & 0.274 & 0.197 \\
\hline Patient 11 & 0.42 & 1.04 & 0.579 & 0.137 \\
\hline
\end{tabular}

